\title{
The effects of $\mathrm{Nd}_{2} \mathrm{O}_{3}$ concentration in the laser emission of $\mathrm{TeO}_{2}-\mathrm{ZnO}$ glasses
}

\author{
L.M. Moreira a , V. Anjos a , M.J.V. Bell ${ }^{\text {a, }}{ }^{*}$, C.A.R. Ramos ${ }^{\text {b }}$, L.R.P. Kassab ${ }^{\text {b }}$, D.J.L. Doualan ${ }^{\text {c }}$, \\ P. Camy ${ }^{\mathrm{C}}$, R. Moncorgé ${ }^{\mathrm{C}}$ \\ a Laboratório de Espectroscopia de Materiais, Departamento de Física, Universidade Federal de Juiz de Fora, Juiz de Fora, MG, Brazil \\ ${ }^{\mathrm{b}}$ Faculdade de Tecnologia de São Paulo, Laboratório de Tecnologia em Materiais Fotônicos e Optoeletrônicos, CEETEPS/UNESP, São Paulo, Brazil \\ ${ }^{\mathrm{c}}$ Centre de recherche sur les Ions, les Matériaux et la Photonique (CIMAP), UMR CNRS-CEA-Ensicaen, Universite de Caen, 6 Boulevard Maréchal Juin, F- \\ 14050, Caen, France
}

\section{A R T I C L E I N F O}

\section{Article history:}

Received 3 February 2016

Received in revised form

8 March 2016

Accepted 13 May 2016

Available online 21 May 2016

\section{Keywords:}

Laser

Neodymium

Tellurite

Glasses

\begin{abstract}
A B S T R A C T
The present work reports the modification introduced by different $\mathrm{Nd}_{2} \mathrm{O}_{3}$ concentration on optical properties and the laser operation of $\mathrm{Nd}^{3+}$ doped $\left(\mathrm{TeO}_{2}-\mathrm{ZnO}\right)$ bulk tellurite glass. The spectroscopic data are analyzed within the Judd Ofelt formalism framework and the results are compared to the fluorescence lifetime and emission measurements to derive values for the quantum efficiency and the stimulated emission cross section of the considered ${ }^{4} \mathrm{~F}_{3 / 2} \rightarrow{ }^{4} \mathrm{I}_{11 / 2}$ infrared laser transition around $1062.5 \mathrm{~nm}$. Continuous-wave laser action is achieved with this bulk tellurite glass by pumping the sample inside a standard plan-concave mirror laser cavity with different output couplers. It is possible to observe coherent emission only for the lower concentration ( $0.5 \%$ (wt.) of $\mathrm{Nd}_{2} \mathrm{O}_{3}$ ). Also laser action could only be observed for this sample with threshold pump power of $73 \mathrm{~mW}$ associated with a laser slope efficiency of $8 \%$ for an output coupler transmission of $4 \%$ indicating that $\mathrm{TeO}_{2}-\mathrm{ZnO}$ are potential materials for laser action. The results presented in this work together with those previously reported with higher concentration $\left(1.0 \%\right.$ (wt) of $\left.\mathrm{Nd}_{2} \mathrm{O}_{3}\right)$ determine the adequate $\mathrm{Nd}_{2} \mathrm{O}_{3}$ concentration for laser action and guide the correct experimental procedure for $\mathrm{TeO}_{2}-\mathrm{ZnO}$ glasses preparation.
\end{abstract}

(C) 2016 Elsevier B.V. All rights reserved.

\section{Introduction}

$\mathrm{Nd}^{3+}$ doped laser materials are very attractive and extensively studied for a wide variety of applications due to their easier 4-levels laser operation mode and usually higher gain cross sections if compared to $\mathrm{Yb}^{3+}$ doped laser materials. These features show to be true even considering applications on short pulse with high peak power laser systems [1]. The search for $\mathrm{Nd}^{3+}$ doped new solid-state laser hosts with specific thermo-mechanical and optical properties is very active, even though laser action of $\mathrm{Nd}^{3+}$ has been observed in a many solid media such as Nd:YAG systems. This is the case of some Nd doped nonlinear tellurite glasses [2-8]. They have a conjunction of good thermo-mechanical properties, typical of crystals, and broad-band spectral properties, typical of glasses. Also, a very interesting combination of large nonlinear refractive index (25 times larger than that of silica), wide transmittance

\footnotetext{
* Corresponding author.

E-mail address: mjbell@fisica.ufjf.br (M.J.V. Bell).
}

range, and low maximum phonon frequency which allows rareearth ion laser emissions in a wide spectral range are observed glasses [9].

In general, crystalline laser hosts lead to higher absorption and emission cross sections, while glasses can be produced in larger volumes with optimal optical quality at lower cost. In order to minimize the non-radiative multiphonon relaxations and to optimize the quantum efficiency of the ${ }^{4} \mathrm{~F}_{3 / 2} \rightarrow{ }^{4} \mathrm{I}_{11 / 2}$ emission of $\mathrm{Nd}^{3+}$, it is also suitable to work with $\mathrm{Nd}^{3+}$ doped host materials with low phonon frequencies and low contents of $\mathrm{OH}$ impurities. In that sense, laser emission of $\mathrm{Nd}^{3+}$ in glasses has been reported in fluorides [10-12], chalcogenides [13], aluminosilicates [14], germanates [15], and, as just mentioned, in tellurite glasses [2-6]. Among oxi-tellurites, the $\mathrm{TeO}_{2}$ - $\mathrm{ZnO}$ glass combines good mechanical stability, chemical durability, high linear and nonlinear refractive indices, together with low phonon energies $\left(\sim 750 \mathrm{~cm}^{-1}\right)$, a wide transmission window $(0.4-6 \mu \mathrm{m})$ and a high rare-earth solubility $[10,16,17]$. The large linear refractive index (1.97) [18] of this tellurite glass imply large stimulated emission cross-sections, 


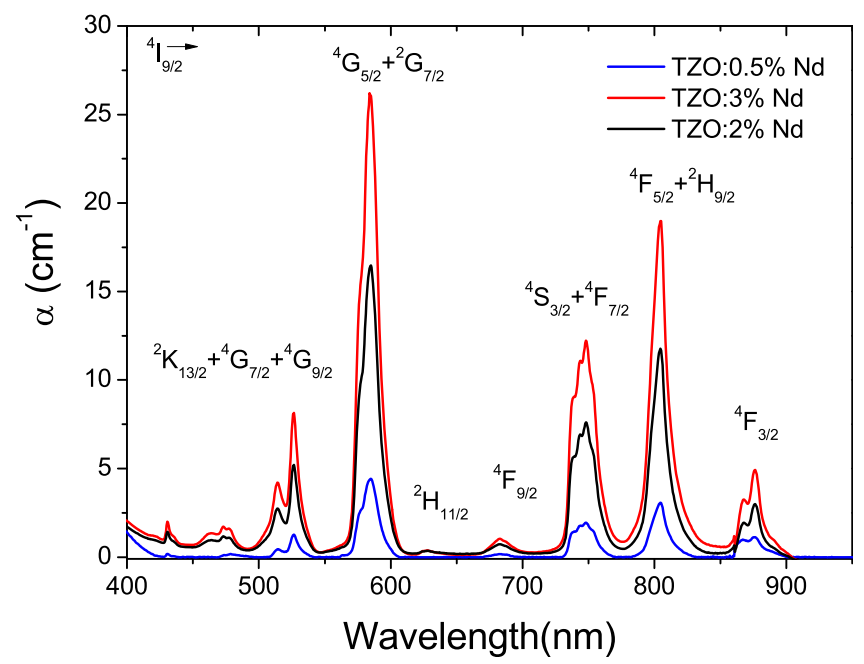

Fig. 1. UV-Vis-NIR absorption spectra for the TZO:Nd samples. The features corresponding to the main absorption transitions of $\mathrm{Nd}^{3+}$ from ${ }^{4} \mathrm{I}_{9 / 2}$ fundamental level to excited levels ${ }^{4} \mathrm{~F}_{3 / 2}(890 \mathrm{~nm}),{ }^{4} \mathrm{~F}_{5 / 2}+{ }^{2} \mathrm{H}_{9 / 2}(808 \mathrm{~nm}),{ }^{4} \mathrm{~F}_{7 / 2}+{ }^{4} \mathrm{~S}_{3 / 2}(750 \mathrm{~nm}),{ }^{4} \mathrm{~F}_{9 /}$ ${ }_{2}(690 \mathrm{~nm}),{ }^{2} \mathrm{H}_{9 / 2},{ }^{4} \mathrm{G}_{5 / 2}+{ }^{2} \mathrm{G}_{7 / 2}(580 \mathrm{~nm})$ and ${ }^{4} \mathrm{G}_{7 / 2}+{ }^{4} \mathrm{G}_{9 / 2}+{ }^{2} \mathrm{~K}_{13 / 2}(520 \mathrm{~nm}){ }^{2} \mathrm{G}_{9 / 2}+{ }^{2} \mathrm{D}_{3}$ $2+{ }^{2} \mathrm{~K}_{15 / 2}(480 \mathrm{~nm})$ have been identified and highlighted in the figure.

sometimes larger than for phosphate glasses [19]. Their high nonlinear optical properties can be used advantageously for the development of Kerr-lens mode-locked subpicosecond lasers. The thermal properties of tellurite glasses have also been investigated and thermal conductivity and thermal diffusivity present reasonable values that encourage the development of optical devices $[20,21]$. Tellurite glasses have also been studied these last years for the possibility of using thin films for the fabrication of rib waveguides [22], and for the possibility of increasing the luminescent quantum yield of rare-earth ions in general with the addition of silver nanoparticles $[23,24]$. Recently an encouraging improvement has been reported regarding the laser performance of a TZO $\left(\mathrm{TeO}_{2}-\right.$ $\mathrm{ZnO}$ ) mixed tellurite and zinc oxide glass doped with $1 \%$ (wt.) of $\mathrm{Nd}_{2} \mathrm{O}_{3}$. In that work, a low laser threshold of $8 \mathrm{~mW}$ and a laser slope efficiency of $21 \%$ were observed [25]. That result motivated the present study that investigates for the first time how the $\mathrm{Nd}_{2} \mathrm{O}_{3}$ concentration influences on the optical properties as well as on the laser emission in the same TZO matrix of ref. [25]. Three different concentrations were analyzed and only at $0.5 \%$ (wt.) of $\mathrm{Nd}_{2} \mathrm{O}_{3}$ true CW laser emission could be obtained. Finally, this paper has the purpose to complement the previous results recently reported in Ref. [25] related to laser action of $\mathrm{Nd}^{3+}$ doped $\mathrm{TeO}_{2}-\mathrm{ZnO}$ glasses and determine the suitable $\mathrm{Nd}_{2} \mathrm{O}_{3}$ concentration for laser action operation.

\section{Experimental details}

The investigated spectroscopic and laser samples were prepared by using the melting quenching technique with the following composition (in wt\%): $85 \% \mathrm{TeO}_{2}-15 \% \mathrm{ZnO}$ (TZO). Three [3] samples were prepared with $0.5 \%, 2.0 \%$, and $3.0 \%$ (wt) of $\mathrm{Nd}_{2} \mathrm{O}_{3}$ ( $\mathrm{TZO}: x \% \mathrm{Nd}$ ),

Table 1

Judd-Ofelt parameters for the TZO:Nd samples.

\begin{tabular}{lllll}
\hline J.O. Parameters $\left(10^{-20} \mathrm{~cm}^{2}\right)$ & & & \\
\hline Sample & $\Omega_{2}$ & $\Omega_{4}$ & $\Omega_{6}$ & RMS \\
\hline TZO:0.5\%Nd & 3.865 & 4.018 & 3.792 & 0.132 \\
TZO:2\%Nd & 3.990 & 4.133 & 4.317 & 0.495 \\
TZO:3\%Nd & 3.633 & 4.908 & 4.633 & 0.400 \\
\hline
\end{tabular}

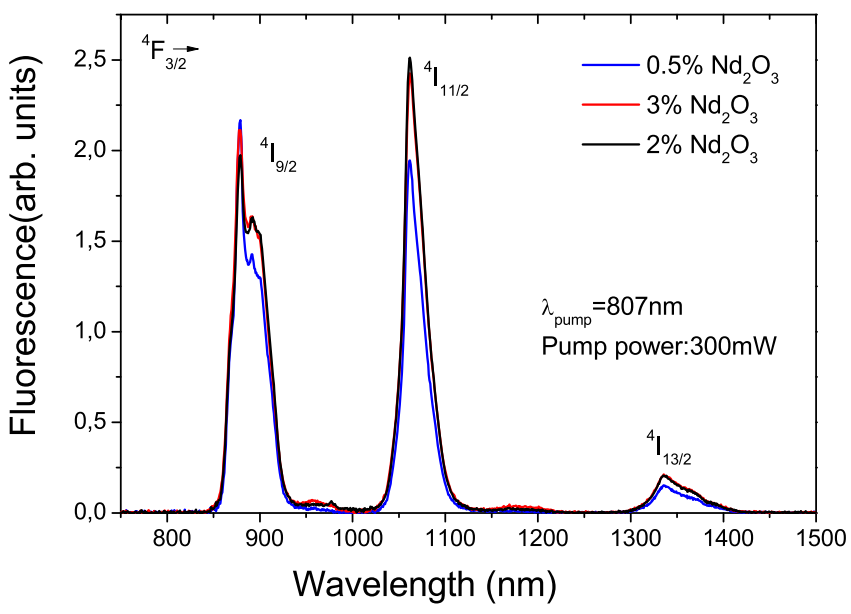

Fig. 2. NIR Fluorescence spectra of the TZO:Nd samples. They were obtained with excitation at $806 \mathrm{~nm}$ within the ${ }^{4} \mathrm{I}_{9 / 2} \rightarrow{ }^{4} \mathrm{~F}_{5 / 2}+{ }^{2} \mathrm{H}_{9 / 2}$ absorption band. It consists of three broad-band emissions peaking around $882 \mathrm{~nm}, 1062 \mathrm{~nm}$ and $1335 \mathrm{~nm}$. They are assigned to the three usual $\mathrm{Nd}^{3+}$ emission transitions, ${ }^{4} \mathrm{~F}_{3 / 2} \rightarrow{ }^{4} \mathrm{I}_{9 / 2},{ }^{4} \mathrm{~F}_{3 / 2} \rightarrow{ }^{4} \mathrm{I}_{11 / 2}$, and ${ }^{4} \mathrm{~F}_{3 / 2} \rightarrow{ }^{4} \mathrm{I}_{13 / 2}$

one for each concentration. Reagents were melted at $800{ }^{\circ} \mathrm{C}$ in a platinum crucible for $20 \mathrm{~min}$, quenched in a pre-heated brass mold, annealed at $325^{\circ} \mathrm{C}$ for $2 \mathrm{~h}$, and cooled down to room temperature during $2 \mathrm{~h}$ to avoid internal stresses.

The absorption spectra were measured in a Perkin-Elmer LAMBDA 9 spectrophotometer in wavelength range from 350 to $1000 \mathrm{~nm}$. The emission spectra was obtained by exciting the samples with a Titanium Safire (Ti:Sa) laser emitting at $808 \mathrm{~nm}$ $(300 \mathrm{~mW}$ ) and chopped at $100 \mathrm{~Hz}$. The light emitted by the sample is collected with an optical fiber detector and a signal is analyzed with the aid of an Optical Spectrum Analyzer (OSA). The fluorescence lifetime measurements were achieved by exciting the sample with a pulsed optical parametric oscillator (OPO) system emitting at $808 \mathrm{~nm}$ ( $7 \mathrm{~mJ}, 5 \mathrm{~ns}$ pulse). The light produced by the sample is collected with a lens to the photomultiplier and finally it hits the detector that sends the signal to the oscilloscope coupled to a computer.

The laser set-up consisted in a standard plan-concave laser resonator. The flat dichroic mirror was highly reflective $(R>99.5 \%)$ around $1064 \mathrm{~nm}$ and with high transmittance ( $\mathrm{T}>95 \%)$ around $808 \mathrm{~nm}$. Two different concave output mirrors with a radius of curvature of $100 \mathrm{~mm}$ and transmissions of $0.8 \%$ and $4 \%$ around $1064 \mathrm{~nm}$ were experimented. The laser samples were prepared in the form of a $10 \times 10 \mathrm{~mm}^{2}$ platelet of $1.65,3.2$ and $3.2 \mathrm{~mm}$ thickness, for the different concentrations with carefully polished and parallel end-faces but without any anti reflection coatings. They were stickled with silver paste on a copper sample holder without any particular cooling, and pumped through the dichroic input mirror by using a CW Ti: Sapphire laser tuned at $806 \mathrm{~nm}$ and focused with a lens of $10 \mathrm{~cm}$ focal length.

\section{Spectroscopic and luminescence properties}

The UV-VIS-NIR absorption (absorption coefficient) spectrum of the three samples investigated in the present work, in the range from $350 \mathrm{~nm}$ to $950 \mathrm{~nm}$, is shown in Fig. 1. The features corresponding to the main absorption transitions of $\mathrm{Nd}^{3+}$ from ${ }^{4} \mathrm{I}_{9 / 2}$ fundamental level to excited levels ${ }^{4} \mathrm{~F}_{3 / 2}$ (890 nm), ${ }^{4} \mathrm{~F}_{5 / 2}+{ }^{2} \mathrm{H}_{9 / 2}$ (808 nm), ${ }^{4} \mathrm{~F}_{7 / 2}+{ }^{4} \mathrm{~S}_{3 / 2}(750 \mathrm{~nm}),{ }^{4} \mathrm{~F}_{9 / 2}(690 \mathrm{~nm}),{ }^{2} \mathrm{H}_{9 / 2},{ }^{4} \mathrm{G}_{5 / 2}+{ }^{2} \mathrm{G}_{7 / 2}$ $(580 \mathrm{~nm})$ and ${ }^{4} \mathrm{G}_{7 / 2}+{ }^{4} \mathrm{G}_{9 / 2}+{ }^{2} \mathrm{~K}_{13 / 2}(520 \mathrm{~nm}){ }^{2} \mathrm{G}_{9 / 2}+{ }^{2} \mathrm{D}_{3 / 2}+{ }^{2} \mathrm{~K}_{15 / 2}$ $(480 \mathrm{~nm})$ have been identified and highlighted in the figure. As 
Table 2

Results from J.O. framework analysis.

\begin{tabular}{|c|c|c|c|c|c|c|}
\hline \multicolumn{7}{|c|}{ Results from J.O. framework analysis } \\
\hline \multirow[t]{2}{*}{ Sample } & \multicolumn{4}{|c|}{ Branching ratios (\%) } & \multirow[t]{2}{*}{ Radiative lifetime $\tau_{\mathrm{R}}(\mu \mathrm{s})$} & \multirow[t]{2}{*}{ Radiative rate $\mathrm{A}\left({ }^{4} \mathrm{~F}_{3 / 2} \rightarrow{ }^{4} \mathrm{I}_{11 / 2}\right)\left(\mathrm{s}^{-1}\right)$} \\
\hline & $\overline{\beta_{9 / 2}}$ & $\beta_{11 / 2}$ & $\beta_{13 / 2}$ & $\overline{\beta_{15 / 2}}$ & & \\
\hline TZO:0.5\%Nd & 44.951 & 45.558 & 9.015 & 0.446 & 198.121 & 2301 \\
\hline TZO:2\%Nd & 43.38 & 46.709 & 9.444 & 0.467 & 182.296 & 2562 \\
\hline TZO:3\%Nd & 44.914 & 45.614 & 9.025 & 0.446 & 161.99 & 2816 \\
\hline
\end{tabular}

Table 3

Branching ratios calculated from the emission spectra from Fig. 2.

\begin{tabular}{lllll}
\hline Sample & \multicolumn{4}{l}{ Branching ratios (\%) } \\
\cline { 2 - 5 } & $\beta_{9 / 2}$ & $\beta_{11 / 2}$ & $\beta_{13 / 2}$ & $\beta_{15 / 2}$ \\
\hline TZO:0.5\%Nd & 45.00 & 47.193 & 7.814 & N/A \\
TZO:2\%Nd & 45.695 & 46.236 & 8.070 & N/A \\
TZO:3\%Nd & 42.355 & 49.195 & 8.449 & N/A \\
\hline
\end{tabular}

expected for a glass, the absorption features appear as broad bands.

Afterwards, the UV-VIS-NIR absorption spectrum was analyzed within the framework of the Judd-Ofelt (J.O.) formalism [26,27]. This led to the J.O. parameters as depicted in Table 1. It was as well possible to derive the radiative rate for the ${ }^{4} \mathrm{~F}_{3 / 2} \rightarrow{ }^{4} \mathrm{I}_{11 / 2}$ emission transition $\mathrm{A}\left({ }^{4} \mathrm{~F}_{3 / 2} \rightarrow{ }^{4} \mathrm{I}_{11 / 2}\right)$, the radiative emission lifetime for the ${ }^{4} \mathrm{~F}_{3 / 2}$ laser emitting level $\tau_{R}$, and branching ratios $\beta_{9 / 2}, \beta_{11 / 2}, \beta_{13 / 2}$ and $\beta_{15 / 2}$ for the ${ }^{4} \mathrm{~F}_{3 / 2} \rightarrow{ }^{4} \mathrm{I}_{9 / 2},{ }^{4} \mathrm{I}_{11 / 2},{ }^{4} \mathrm{I}_{13 / 2}$ and ${ }^{4} \mathrm{I}_{15 / 2}$ emission transitions (Fig. 2) around $900 \mathrm{~nm}, 1060 \mathrm{~nm}, 1350 \mathrm{~nm}$ and $1800 \mathrm{~nm}$ (not observed), respectively. These results are displayed in Table 2.

Fig. 2 shows the near infrared (NIR) luminescence spectra of the samples. They were obtained with excitation at $806 \mathrm{~nm}$ within the ${ }^{4} \mathrm{I}_{9 / 2} \rightarrow{ }^{4} \mathrm{~F}_{5 / 2}+{ }^{2} \mathrm{H}_{9 / 2}$ absorption band (Fig. 1). It consists of three broad-band emissions peaking around $882 \mathrm{~nm}, 1062 \mathrm{~nm}$ and $1335 \mathrm{~nm}$. They are assigned to the three usual $\mathrm{Nd}^{3+}$ emission transitions, ${ }^{4} \mathrm{~F}_{3 / 2} \rightarrow{ }^{4} \mathrm{I}_{9 / 2},{ }^{4} \mathrm{~F}_{3 / 2} \rightarrow{ }^{4} \mathrm{I}_{11 / 2}$, and ${ }^{4} \mathrm{~F}_{3 / 2} \rightarrow{ }^{4} \mathrm{I}_{13 / 2}$, and associated with the experimental branching ratios (fraction of photons emitted within each of the emission transitions) with $\beta_{i}=\frac{\int_{i} \lambda I_{i}(\lambda) d \lambda}{\sum_{i=1,2,3} \int_{i} \lambda I_{i}(\lambda) d \lambda}$ and $i=9 / 2,11 / 2$ and $15 / 2$, respectively. The results obtained are close to those found from the J.O. treatment (Table 2). In view of the good RMS values obtained with the J.O. treatment, and the more delicate procedure to get perfectly calibrated emission spectra (problem of correction from the spectral response of the equipment and problem of reabsorption which always affect the shape and the intensity of the emission transition around $900 \mathrm{~nm}$ ), a better credit will be given in the following for the values derived with the J.O. analysis. It is also worth noting here that no visible upconversion emission was observed with the considered excitation.

Table 4 shows the fluorescence decay lifetimes $\left(\tau_{\mathrm{f}}\right)$ associated with the ${ }^{4} \mathrm{~F}_{3 / 2} \rightarrow{ }^{4} \mathrm{I}_{11 / 2}$ emission transition around $1062 \mathrm{~nm}$. The decays were fully exponential. Therefore, according to the radiative lifetime $\left(\tau_{R}\right)$ in Table 2 , the quantum efficiency for the ${ }^{4} \mathrm{~F}_{3 / 2} \rightarrow{ }^{4} \mathrm{I}_{11 / 2}$ emission transition, i.e. $\eta=\tau_{f} / \tau_{R}$, are displayed in Table 4 . They are lower than $80 \%$ for $2 \%$ and $3 \%$ (wt.) of $\mathrm{Nd}_{2} \mathrm{O}_{3}$. This means that no concentration quenching occurs in this material at the dopant concentration of $0.5 \%$ (wt.) of $\mathrm{Nd}_{2} \mathrm{O}_{3}$; this is not case, for instance, for the higher concentration ( $2 \%$ and $3 \%(w t)$.$) . The decrease of the$ fluorescence lifetime is related to the concentration quenching due to the interaction between pairs of $\mathrm{Nd}^{3+}$. As the $\mathrm{Nd}$ concentration increases, the distance between $\mathrm{Nd}^{3+}$ ions is reduced. As a result, energy transfer processes can take place. The most important nonradiative energy transfer mechanisms for $\mathrm{Nd}^{3+}$ are due to cross relaxation (represented by ${ }^{4} \mathrm{~F}_{3 / 2},{ }^{4} \mathrm{I}_{9 / 2} \rightarrow{ }^{4} \mathrm{I}_{15 / 2},{ }^{4} \mathrm{I}_{15 / 2}$ and ${ }^{4} \mathrm{~F}_{3 / 2},{ }^{4} \mathrm{I}_{9}$ ${ }_{2} \rightarrow{ }^{4} \mathrm{I}_{13 / 2},{ }^{4} \mathrm{I}_{15 / 2}$ ), and energy migration ${ }^{4} \mathrm{~F}_{3 / 2},{ }^{4} \mathrm{I}_{9 / 2} \rightarrow{ }^{4} \mathrm{I}_{9 / 2},{ }^{4} \mathrm{~F}_{3 / 2}$ [28].

Also, the higher $\mathrm{Nd}_{2} \mathrm{O}_{3}$ concentration samples display lower optical quality and thermal resistance.

Based on the derived spectroscopic and luminescence data, the emission spectrum reported in Fig. 2 can be used to estimate the stimulated emission cross section of the considered ${ }^{4} \mathrm{~F}_{3 / 2} \rightarrow{ }^{4} \mathrm{I}_{11 / 2}$ emission transition peaking around $1062 \mathrm{~nm}$ by using the following expression [29]:

$\sigma_{e m}(\lambda)=\frac{\lambda^{4}}{8 \pi c n^{2} \Delta \lambda} \cdot A\left({ }^{4} F_{3 / 2} \rightarrow{ }^{4} I_{9 / 2}\right)$

where $\Delta \lambda$ ( $=24 \mathrm{~nm}$ for all three samples) stands for the width of the emission line at half maximum and $\mathrm{n} \approx 1.97$ is the refractive index of the material [18]. This expression leads to the emission cross sections $\left(\sigma_{\mathrm{em}}\right)$ shown in Table 3 for all the samples.

\section{4. $C W$ laser results}

Although all three samples were tested for laser emission, true CW laser action could only be obtained with the lowest concentration ( $0.5 \%$ (wt.) of $\left.\mathrm{Nd}_{2} \mathrm{O}_{3}\right)$. Fig. 4 shows the laser output versus absorbed pump power curves obtained after pumping the sample around $806 \mathrm{~nm}$. Threshold pump powers $\left(\mathrm{P}_{\text {th }}\right)$ of $53 \mathrm{~mW}$ and $73 \mathrm{~mW}$ (as extrapolated with the straight lines reported in the figure) and slope efficiencies of $6.6 \%$ and $8.2 \%$ were obtained for the output coupler transmissions of $0.8 \%$ and $4 \%$, respectively.

These slopes can be considered to estimate the intrinsic roundtrip optical losses (L) noted inside the laser cavity and to have an idea of the optical quality of the laser sample. For that purpose, the Findlay-Clay or technique [30] should be applied. It consists in a plot of $\mathrm{P}_{\text {th }}$ versus the transmission $T$ of the output coupler, through the expression below where $\boldsymbol{a}$ and $\boldsymbol{b}$ are obtained from Ref. [31]:

$P_{t h}=a T+b$

with $[28]$

$a=\frac{h v_{L} S}{2 \eta_{q} \sigma_{e m} \eta_{e} \tau_{R} \eta_{R} \varepsilon_{P} \eta_{P}}, b=a L$

Table 4

Fluorescence lifetime decay, quantum efficiency and emission cross section.

\begin{tabular}{|c|c|c|c|}
\hline Sample & Fluorescence lifetime decay $\tau_{\mathrm{f}}(\mu \mathrm{s})$ & Quantum efficiency $\eta(\%)$ & Emission cross section $\sigma_{\mathrm{em}}(1062 \mathrm{~nm})\left(10^{-20} \mathrm{~cm}^{2}\right)$ \\
\hline TZO:0.5\%Nd & $158 \pm 1$ & $79.750 \pm 0.005$ & $4.2 \pm 0.2$ \\
\hline TZO:2\%Nd & $124 \pm 1$ & $68.019 \pm 0.005$ & $4.6 \pm 0.2$ \\
\hline TZO:3\%Nd & $90.1 \pm 0.7$ & $55.617 \pm 0.004$ & $5.10 \pm 0.3$ \\
\hline
\end{tabular}




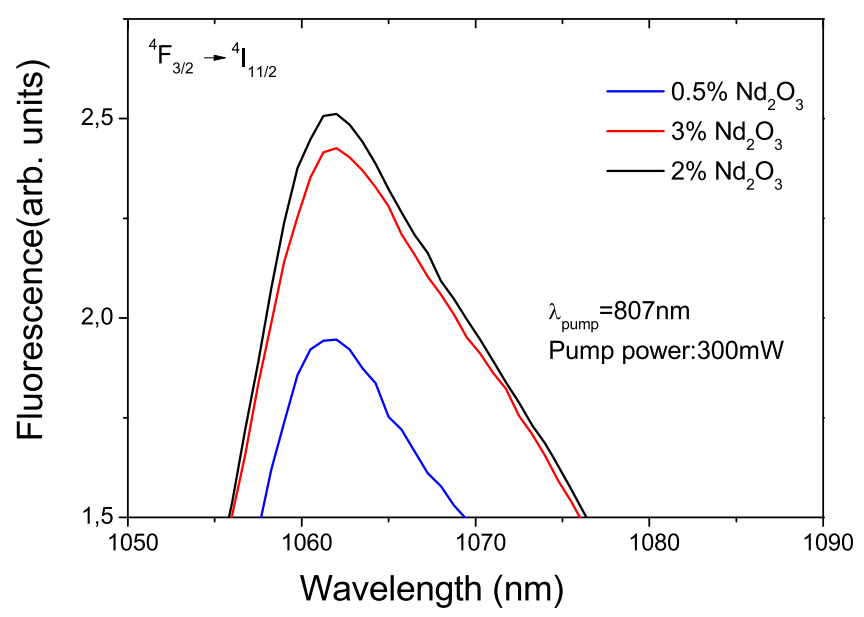

Fig. 3. NIR Fluorescence spectra of the TZO:Nd samples for the ${ }^{4} F_{3 / 2} \rightarrow{ }^{4} I_{11 / 2}$, $(1062 \mathrm{~nm})$ transition. Zooming in this part of the emission spectra it is possible to notice the quenching effect in the TZO: $3 \% \mathrm{Nd}$ sample emission spectrum.

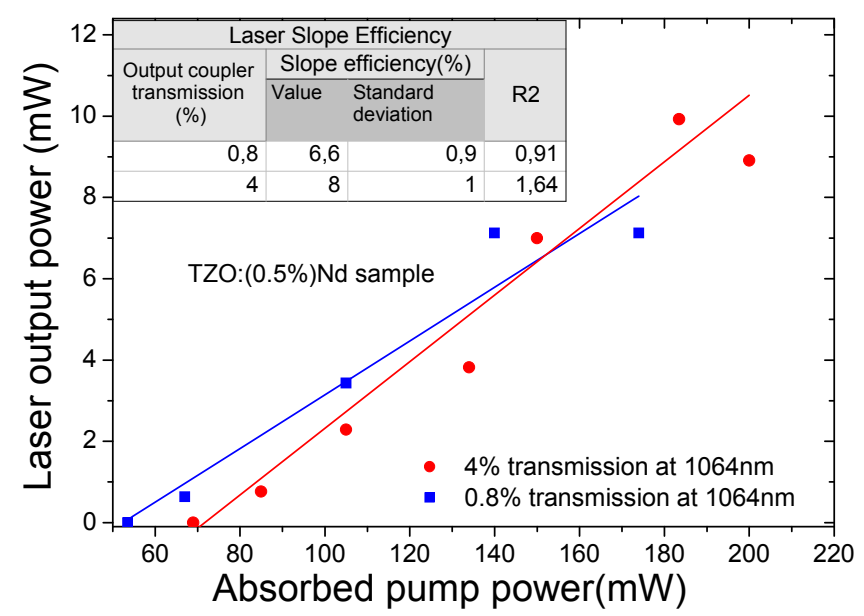

Fig. 4. Laser output power versus absorbed pump power curves obtained after pumping the TZO glass sample around $806 \mathrm{~nm}$, for the output coupler transmissions of $0.8 \%$, and $4 \%$ for the TZO:0.5\%Nd sample. Threshold pump powers $\left(\mathrm{P}_{\text {th }}\right)$ of $53 \mathrm{~mW}$ and $73 \mathrm{~mW}$ (as extrapolated with the straight lines reported in the figure) and slope efficiencies of $6.6 \%$ and $8.2 \%$ were obtained for the output coupler transmissions of $0.8 \%$ and $4 \%$, respectively.

In equation [2], $v_{L}$ stands for the laser emission frequency $S \approx \pi\left(\omega_{P}^{2}+\omega_{C}^{2}\right) / 2$ with $\omega_{P}^{2}$ and $\omega_{C}^{2}$ the pump and cavity mode waist

Table 5

Laser cavity parameters of TZO: $\mathrm{Nd}^{3+}$ tellurite glasses. $\lambda_{\text {laser }}, \lambda_{\text {pump}}, \eta_{\text {slope }}, \mathrm{T}, \mathrm{Pth}, \sigma_{\mathrm{em}}$ means emission wavelength, pumping wavelength, slope efficiency, output coupled transmission, threshold and stimulated emission cross section.

\begin{tabular}{lllll}
\hline Parameter & \multicolumn{4}{l}{ TZO:x\%Nd glasses } \\
\cline { 2 - 5 } & Bell et al. [25] & This work & \\
\hline $\mathrm{Nd}_{2} \mathrm{O}_{3}(\%(\mathrm{wt}))$ & 1 & 0.5 & 2 & 3 \\
$\lambda_{\text {laser }}(\mathrm{nm})$ & 1062 & 1062 & $\mathrm{~N} / \mathrm{A}$ & $\mathrm{N} / \mathrm{A}$ \\
$\lambda_{\text {pump }}(\mathrm{nm})$ & 806 & 806 & 806 & 806 \\
$\eta_{\text {slope }}(\%)$ & 21 & 8 & $\mathrm{~N} / \mathrm{A}$ & $\mathrm{N} / \mathrm{A}$ \\
$P_{\text {th }}(\mathrm{mW})$ & 8 & 73 & $\mathrm{~N} / \mathrm{A}$ & $\mathrm{N} / \mathrm{A}$ \\
$\mathrm{T}(\%)$ & 2.7 & 4 & $\mathrm{~N} / \mathrm{A}$ & $\mathrm{N} / \mathrm{A}$ \\
$\tau_{f}, \tau_{R}(\mu \mathrm{s})$ & 210,217 & 158,198 & 124,182 & 90,162 \\
$\eta_{\text {Quantum }}(\%)$ & 95 & 80 & 68 & 56 \\
$\Delta \lambda(\mathrm{nm})$ & 29 & 24 & 24 & 24 \\
$\sigma_{\text {em }}\left(10^{-20} \mathrm{~cm}^{2}\right)$ & 3.1 & 4.2 & 4.6 & 5.1 \\
\hline
\end{tabular}

radii, $\sigma_{e m}$ is the stimulated emission cross section $\eta_{e}=\sigma_{e m}^{\text {eff }} / \sigma_{e m}$, with $\sigma_{e m}^{\text {eff }}=\left(\sigma_{e m}+\sigma_{a}-\sigma_{e s a}\right), \eta_{q}=\lambda_{P} / \lambda_{L}$ the quantum conversion efficiency, $\eta_{R}=\tau_{f} / \tau_{R}$ the radiative quantum efficiency, $\varepsilon_{P}$ the pump efficiency, i.e. the fraction of absorbed pump photons in the laser levels, and $\eta_{P}=1-\exp \left(-\sigma_{P} N l\right)$ the fraction of absorbed versus incident pump photons. Even if not detailing the values of all these parameters, the plot (Fig. 3) can be used to extrapolate threshold pump powers from the straight lines in the graph. It leads to roundtrip optical losses $\mathrm{L} \approx 7.2 \%$. Therefore, it can be concluded that the laser material introduces single pass optical losses less than $3.6 \%$, which is higher than in ref. [25] but reasonable.

Finally, Table 5 gives a comparison between the laser results of this work and those obtained recently for the same glass host with $1 \%(w t)$ of $\mathrm{Nd}_{2} \mathrm{O}_{3}$ [25]. It is possible to notice that for the lower concentration $(0.5 \%(\mathrm{wt}))$ it is already possible to observe $1062 \mathrm{~nm}$ CW laser action even though at a modest efficiency of $8.2 \%$ at $4 \%$ transmission and a laser threshold of $73 \mathrm{~mW}$, for $806 \mathrm{~nm}$ pumping. In this case laser action is obtained for higher threshold pump power probably because of the higher single pass optical loss that is of $3.6 \%$ whereas for the sample with $1 \%$ (wt) of $\mathrm{Nd}_{2} \mathrm{O}_{3}$ this value is of $0.2 \%$ [25]. However, the sample with $0.5 \%$ (wt) exhibits features comparable to the sample with $1 \%(\mathrm{wt})$, a large emission cross section $\left(4.2 \times 10^{-2} \mathrm{~cm}^{2}\right)$, and a similar value of the wide emission bandwidth of $24 \mathrm{~nm}$ ( $29 \mathrm{~nm}$ for the $1 \%$ (wt) of $\mathrm{Nd}_{2} \mathrm{O}_{3}$ ). On the other hand, a lower fluorescence lifetime of $158 \mu$ s is obtained, whereas for $1 \%$ (wt) of $\mathrm{Nd}_{2} \mathrm{O}_{3}$ it is of $210 \mu \mathrm{s}$ [25]. Moreover, samples with higher concentrations than $1 \%(w t)$ exhibited no laser emission probably due to cluster formation and concentration quenching. Finally considering the previous results recently reported [25] we come to the conclusion that $\mathrm{TeO}_{2}-\mathrm{ZnO}$ glasses are suitable for laser action when prepared with $0.5 \%$ and $1 \%$ (wt) of $\mathrm{Nd}_{2} \mathrm{O}_{3}$.

\section{Conclusions}

We have demonstrated true $\mathrm{CW}$ laser action in a bulk $\mathrm{Nd}^{3+}$ doped $\mathrm{TeO}_{2}$-ZnO tellurite glass at $1062 \mathrm{~nm}$, with an acceptable laser threshold of $73 \mathrm{~mW}$ and a slope efficiency of $8.2 \%$ for an output mirror transmission of $4 \%$. Such laser result remains modest specially if compared to the result obtained by Bell et al.[25]. So the present work complements those in ref. [25] as it confirms that the best concentration for low threshold pump power is $1 \%(\mathrm{wt})$ of $\mathrm{Nd}_{2} \mathrm{O}_{3}$. It also shows that laser operation is possible for $0.5 \%$ (wt) because of the reasonable quality achieved, attested by low internal losses, together with a fairly long emission lifetime of about $158 \mu \mathrm{s}$, an emission quantum efficiency of 0.8 and a high stimulated emission cross section of $4.2 \times 10^{-20} \mathrm{~cm}^{2}$, for a wide emission bandwidth of $24 \mathrm{~nm}$.

The main contribution of the present investigation lies in the possibility of establishing the $\mathrm{Nd}_{2} \mathrm{O}_{3}$ concentration range for laser action operation in $\mathrm{TeO}_{2}-\mathrm{ZnO}$ glasses, guiding the correct method for the preparation of these glasses for solid state laser applications.

\section{Acknowledgments}

The authors acknowledge the financial support of the Brazilian agencies CAPES, National Institute of Photonics (INCT Project/ CNPq), CAPES/COFECUB, and CNPq.

\section{References}

[1] F. Träger (Ed.), "Handbook of Lasers and Optics", Solid-state Lasers/Nd Lasers, Springer, New-York, 2007, pp. 636-648.

[2] J.C. Michel, D. Morin, F. Auzel, Propriétés spectroscopiques et effet laser d'un verre tellurite et d'un verre phosphate dopés en néodyme, Rev. Phys. Appl. 13 (1978) 859.

[3] A. Miguel, J. Azkargorta, R. Morea, I. Iparraguirre, J. Gonzalo, J. Fermamdez, 
R. Balda, Spectral study of the stimulated emission of $\mathrm{Nd}^{3+}$ in fluorotellurite bulk glass, Opt. Expr. 21 (2013) 009298.

[4] H. Kalaycioglu, H. Cankaya, G. Ozen, L. Ovecoglu, A. Sennaroglu, Lasing at 1065 $\mathrm{nm}$ in bulk $\mathrm{Nd}^{3+}$-doped telluride-tungstate glass, Opt. Commun. 281 (2008) 6056-6060.

[5] I. Iparraguirre, J. Azkargorta, J.M. Fernández-Navarro, M. Al-Saleh, J. Fernández, R. Balda, Laser action and upconversion of $\mathrm{Nd}^{3+}$ in tellurite bulk glass, J. NonCryst. Solids 353 (8-10) (2007) 990-992.

[6] N. Lei, B. Xu, Z.H. Jiang, Ti-sapphire laser pumped Nd-tellurite glass laser, Opt. Commun. 127 (4-6) (1996) 263-265.

[7] W. Ryba-Romanowski, S. Golab, L. Cichosz, B.J. Ttzebiatowska, Influence of temperature and acceptor concentration on energy transfer from $\mathrm{Nd}^{3+}$ to $\mathrm{Yb}^{3+}$ and from $\mathrm{Yb}^{3+}$ to $\mathrm{Er}^{3+}$ in tellurite glass, J. Non-Cryst. Solids 105 (1988) 295.

[8] J.S. Wang, E.M. Vogel, E. Snitzer, J.L. Jackel, V.L. da Silva, Y. Silberberg, $1.3 \mu \mathrm{m}$ emission of neodymium and praseodymium in tellurite-based glasses, J. Non Cryst. Solids 178 (1994) 109.

[9] R. A. H. El-Mallawany, Tellurite Glasses Handbook-physical Properties and Data, (CRC Boca Raton, FL2001).

[10] R.R. Petrin, M.L. Kliewer, J.T. Beasley, R.C. Powell, I.D. Aggarwal, R.C. Ginther, Spectroscopy and laser operation of Nd:ZBAN glass, IEEE J. Quantum Electron. 27 (1991) 1031-1038.

[11] J. Azkargorta, I. Iparraguirre, R. Balda, J. Fernández, E. Dénoue, J.L. Adam, Spectroscopic and laser properties of $\mathrm{Nd}^{3+}$ in BIGaZLuTMn fluoride glass, IEEE J. Quantum Electron. 30 (1994) 1862-1867.

[12] J. Azkargorta, I. Iparraguirre, R. Balda, J. Fernández, On the origin of bichromatic laser emission in $\mathrm{Nd}^{3+}$-doped fluoride glasses, Opt. Expr. 16 (16) (2008) $11894-11906$

[13] T. Schweizer, D.W. Hewak, D.N. Payne, T. Jensen, G. Huber, Rare-earth doped chalcogenide glass laser, Electron. Lett. 32 (1996) 666-667.

[14] D.F. de Sousa, L.A.O. Nunes, J.H. Rohling, M.L. Baesso, Laser emission at 1077 $\mathrm{nm}$ in $\mathrm{Nd}^{3+}$-doped calcium aluminosilicate glass, Appl. Phys. B 77 (2003) 59-63.

[15] J. Fernandez, I. Iparraguirre, R. Balda, J. Azkargorta, M. Voda, J.M. FernandezNavarro, Laser action and upconversion of $\mathrm{Nd}^{3+}$ in lead-niobium-germanate bulk glass, Opt. Mater. 25 (2) (2004) 185-191.

[16] J.S. Wang, E.M. Vogel, E. Snitzer, Tellurite glass: a new candidate for fiber devices, Opt. Mater. 3 (3) (1994) 187-203.

[17] A. Jha, S. Shen, M. Naftaly, Structural origin of spectral broadening of $1.5-\mu \mathrm{m}$ emission in $\mathrm{Er}^{3+}$ doped tellurite glasses, Phys. Rev. B 62 (10) (2000) 6215-6227.

[18] H.A.A. Sidek, S. Rosmawati, Z.A. Talib, M.K. Halimah, W.M. Daud, Synthesis and optical properties of $\mathrm{ZnO}^{-\mathrm{TeO}_{2}}$ glass system, Am. J. Appl. Sci. 6 (8) (2009) 1489-1494.

[19] M.J. Weber, Science and technology of laser glass, J. Non Cryst. Solids 123 $(1-3)(1990) 208-222$.

[20] A.P. Carmo, M.J.V. Bell, V. Anjos, R. de Almeida, D. da Silva, L.R.P. Kassab Thermo-optical properties of tellurite glasses doped with $\mathrm{Eu}^{3+}$ and $\mathrm{Au}$ nanoparticles, J. Phys. D-Appl. Phys. 42 (2009) 155404.

[21] A.P. Silva, A.P. Carmo, V. Anjos, M.J.V. Bell, L.R.P. Kassab, R.A. Pinto, Temperature coefficient of optical path of tellurite glasses doped with gold nanoparticles, Opt. Mater. 34 (2011) 239-243.

[22] V.D. Del Cacho, A.L. Siarkowsi, N. Morimoto, H.V. Borges, L.R.P. Kassab Fabrication and characterization of $\mathrm{TeO}_{2}-\mathrm{ZnO}$ rib waveguides, ECS Trans. 31 (2010) 219.

[23] L.R.P. Kassab, L.F. Freitas, T.A.A. de Assumpção, D.M. da Silva, C.B. de Araújo, Frequency upconversion properties of $\mathrm{Ag}$ : $\mathrm{TeO}_{2}-\mathrm{ZnO}$ nanocomposites codoped with $\mathrm{Yb}^{3+}$ and $\mathrm{Tm}^{3+}$ ions, Appl. Phys. B 104 (2011) 1029.

[24] T.A.A. de Assumpção, M.E. Camilo, L.R.P. Kassab, A.S.L. Gomes, C.B. de Araújo N.U. Wetter, Frequency upconversion properties of $\mathrm{Tm}^{3+}$ doped $\mathrm{TeO}_{2}-\mathrm{ZnO}$ glasses containing silver nanoparticles, J. Alloy. Comp. 536 (2012) S504-S506

[25] M.J.V. Bell, V. Anjos, L.M. Moreira, R.F. Falci, L.R.P. Kassab, D.S. da Silva, J.L. Doualan, P. Camy, R. Moncorgé, Laser emission of a Nd-doped mixed tellurite and zinc oxide glass, J. Opt. Soc. Am. B 31 (2014) 1590-1594.

[26] B.R. Judd, Optical absorption intensities of rare-earth ions, Phys. Rev. 127 (1962) 750 .

[27] G.S. Ofelt, Intensities of crystal spectra of rare-earth ions, J. Chem. Phys. 37 (1962) 511.

[28] C. Jacinto, S.L. Oliveira, L.A.O. Nunes, J.D. Myers, M.J. Myers, T. Catunda, Phys, Rev. B 73 (2006) 125107.

[29] W.K. Krupke, Induced emission cross-sections in neodymium laser glasses, IEEE J. Quant. Electron. QE 10 (1974) 450.

[30] D. Findlay, R.A. Clay, The measurement of internal losses in 4-levels lasers, Phys. Lett. 20 (1966) 277-278.

[31] R. Moncorgé, Current topics in rare-earth lasers, Springer series in Materials Science, in: G. Liu, B. Jacquier (Eds.), Spectroscopic Properties of Rare-earths in Optical Materials, 2005, pp. 320-378. Chap. 6. 